\begin{tabular}{|l|l|l|}
\hline \multicolumn{2}{|c|}{ PublisherInfo } \\
\hline \hline PublisherName & $:$ & BioMed Central \\
\hline \hline PublisherLocation & $:$ & London \\
\hline \hline PublisherImprintName & $:$ & BioMed Central \\
\hline \hline
\end{tabular}

\title{
Prognosis and treatment of small breast carcinomas
}

\begin{tabular}{|l|l|l||}
\hline \multicolumn{2}{|c|}{ ArticleInfo } \\
\hline \hline ArticleID & $:$ & 3760 \\
\hline \hline ArticleDOI & $:$ & $10.1186 /$ bcr-2001-68442 \\
\hline \hline ArticleCitationID & $:$ & 68442 \\
\hline \hline ArticleSequenceNumber & $:$ & 32 \\
\hline \hline ArticleCategory & $:$ & Paper Report \\
\hline \hline ArticleFirstPage & $:$ & 1 \\
\hline \hline ArticleLastPage & $:$ & 4 \\
\hline \hline & & RegistrationDate $: 2001-8-20$ \\
& $:$ & Received \\
\hline ArticleHistory & & Accepted 2001-3-8 \\
& $:$ 2001-8-20 \\
\hline \hline ArticleCopyright & $:$ & Biomed Central Ltd2001 \\
\hline \hline ArticleGrants & $:$ & \\
\hline \hline ArticleContext & $:$ & 1305833 \\
\hline \hline
\end{tabular}




\section{Frances O'Malley, Affl}

Aff1 Mount Sinai Hospital, Toronto, Canada

\section{Keywords}

\section{Chemotherapy, lymph node negative, prognosis, tumor size}

\section{Context}

Although many clinical trials have assessed the efficacy of adjuvant therapy in women with lymph node negative (LNN) disease, few trials have included enough women with tumors $1 \mathrm{~cm}$ in diameter or less to draw definite conclusions about the benefit of this therapy in this cohort of patients.

The aim of this study was to determine if pooling data from several large NSABP trials from women with small tumors would provide information on determining prognosis in women with tumors $=1 \mathrm{~cm}$, as well as to provide guidance with respect to the use of adjuvant therapy in this population of women.

\section{Significant findings}

There were over 3000 patients with ER-negative tumors enrolled in the B-13, B-19 and B-06 trials; however, only 235 (7.8\%) of these women had tumors $=1 \mathrm{~cm}$ and LNN disease. In this small cohort, the 8 -year recurrence-free survival for patients who were treated by surgery was $81 \%$ versus $91 \%$ for those patients treated with chemotherapy $(P=0.06)$. While the aim of this study was to focus on patients with tumors $=1 \mathrm{~cm}$, the majority of patients in both groups had tumors reported as exactly $1 \mathrm{~cm}$ (which is likely to be a 'rounding off' effect), while only 36 patients had tumors $=5 \mathrm{~mm}$ (T1a). Almost 4000 patients with ER-positive, LNN disease were enrolled in the NSABP B-14, B-20 and B-06 trials. Of these, 1024 patients were included in the outcome analysis. However, approximately $60 \%$ of tumors in the control and chemotherapy groups were exactly $1 \mathrm{~cm}$ (which is again likely to be a 'rounding off' effect), while only $6 \%$ in both the control (17 patients) and chemotherapy plus tamoxifen (13 patients) groups had tumors $=5 \mathrm{~mm}$. Clearly, the patients with T1a tumors represent a minute subset of all the patients enrolled in the clinical trials. 


\title{
Comments
}

This study attempts to address whether adjuvant therapy should be used in patients with small tumors. This is a retrospective analysis of the clinical outcome of patients with tumors $=1 \mathrm{~cm}$ in diameter and LNN disease who were recruited to several NSABP trials between 1976 and 1991. However, even the cumulative number of patients remains too small to allow definitive conclusions. A thoughtful review of the limitations of this study are outlined in an accompanying editorial by Lippman and Hayes (see Additional information). The authors address the risk/benefit issue with respect to the use of chemotherapy in a subgroup of patients who would otherwise be expected to have a very good prognosis. They discuss the important issue of absolute prognosis; it would be expected that giving chemotherapy to a patient with a $95 \%$ chance of survival after surgery alone would increase her absolute odds of survival by no more than $2 \%$. The editorial also highlights the miniscule numbers of patients with T1a $(=5 \mathrm{~mm})$ tumors and tumors $6-9 \mathrm{~mm}$ included in the outcome analysis and it is particularly in patients with tumors in this size range where the risks of chemotherapy may indeed exceed the benefits.

The authors conclude that chemotherapy and/or tamoxifen 'should be considered' for all patients with tumors $<1 \mathrm{~cm}$ and LNN disease. However, there was no difference in overall survival between ERnegative patients treated with surgery alone versus those treated with surgery and chemotherapy $(93 \%$ and $91 \%, P=0.65$ ). For ER-positive patients, survival differed only for those patients treated with tamoxifen versus those treated with tamoxifen and other chemotherapy $(92 \%$ and $97 \%$ respectively, $\mathrm{P}=$ 0.01 ). While there is little doubt that chemotherapy is efficacious in this group of patients, it remains debatable as to whether the benefits of chemotherapy outweigh the risks, particularly in patients with T1a tumors where the event-free survival may be greater than $95 \%$.

\section{Methods}

Women with tumors $=1 \mathrm{~cm}$ and LNN disease were selected from several NSABP randomized control trials, investigating the efficacy of various treatments: various chemotherapeutic regimens (B-13, B-19); tamoxifen, either alone (B-14) or in combination with other chemotherapy (B-20); and lumpectomy versus mastectomy (B-06). Kaplan-Meier curves were used to describe distributions of time to recurrence-free survival and event-free survival. Although the studies had different lengths of follow-up, all had an average follow-up of at least 8 years; thus only follow-up information up to 8 years was included in the analysis. Analysis for women with estrogen receptor (ER)-positive tumors was reported separately from those with ER-negative tumors.

\section{Additional information}

\author{
Lippman ME, Hayes DF: Adjuvant therapy for all patients with breast cancer.
}


J Natl Cancer Inst 2001, 93:80-82 (PubMed abstract).

\section{References}

1. Fisher B, Dignam J, Tan-Chiu E, Anderson S, Fisher ER, Wittliff JL, Wolmark N: Prognosis and treatment of patients with breast tumors of one centimeter or less and negative axillary lymph nodes. $\mathrm{J}$ Natl Cancer Inst. 2001, 93: 112-120. 